Genet. Sel. Evol. 40 (2008) 1

Available online at:

(C) INRA, EDP Sciences, 2008

www.gse-journal.org

DOI: $10.1051 / \mathrm{gse}: 2007037$

\title{
GSE NEWS AND EDITORIAL ANNOUNCEMENTS
}

With the New Year comes the opportunity to make a quick assessment of the journal's production in the past year and to announce some changes for 2008.

From October 2006 to September 2007, GSE has received 119 new manuscripts among which 64 have been rejected, 29 accepted and 26 are still in evaluation. Additionally, 25 articles submitted before October 2006 have been accepted. Thus the number of submitted manuscripts per year has remained constant while the number of accepted articles has increased by about $22 \%$. This reflects in part our policy of requesting shorter manuscripts to provide more space for publication while keeping the total number of pages to around 700. Accepted articles originate from 15 countries with France leading (11), followed by the USA (7), Australia (5), China, Denmark, Spain and UK (4), Finland, Germany and Norway (3), the Netherlands (2), and finally Canada, Italy, Poland and Portugal. Of these 54 accepted articles, 42 deal with methodologies of quantitative genetics and their applications to animal selection and characterization, five address genetic diversity of populations and breeds and seven fall in the field of molecular genetics. These figures confirm those of the previous year and that GSE is now recognized as a journal specializing on papers with a strong methodological dimension to help understand, maintain and exploit genetic diversity.

In 2007, changes have taken place on the editorial board: (1) Christian Looft has resigned and we thank him warmly for his active collaboration with the journal since 2001 and (2) Magali San Cristobal from the Institut National de la Recherche Agronomique (France) has joined us bringing her expertise in the field of statistical genetics.

Another change is the creation of a new section "Selected Papers" on the website of GSE (http://www.gse-journal.org/). It contains a regularly updated selection of freely accessible articles published in GSE.

With our on-going goal to promote "Open Access" publishing for wide and easy access to all published scientific information, we are renewing our offer of the "Open Choice" option at the attractive fee of 750 euros for papers published in 2008 (without VAT), which is still well under the real publication cost. With this option, authors can have their articles accepted for publication made available on-line to all interested readers (subscribers or non-subscribers) as soon as they are published instead of one year after.

Finally, we are pleased to announce that since September 2007, the entire collection of back issues of GSE and of its parent journal (Annales de Génétique et de Sélection Animales) from 1969 till 1999 is available online (http://www.gse-journal.org/) and free of charge. This electronic archive contains all the articles in searchable PDF format and offers an essential database of scientific knowledge in animal genetics.

It is our pleasure to wish you a very happy and scientifically productive year 2008. 